\title{
Educação Ambiental e o trabalho com valores: lembranças de professoras sobre suas experiências em um projeto de formação continuada de professores
}

\section{Environmental Education and the work with values: memories of teachers about their experiences in a in-service teacher training project}

\section{Educación Ambiental y el trabajo con valores: recuerdos de profesoras sobre sus experiencias en un proyecto de formación continuada de profesores}

\author{
Gabriela Rodrigues Longo ${ }^{1}$ \\ Dalva Maria Bianchini Bonotto ${ }^{2}$
}

\begin{abstract}
Resumo
Nossa pesquisa se concentra na formação continuada de professores em Educação Ambiental (EA) e sua dimensão axiológica, tendo em vista que diversos autores, que discutem a dimensão valorativa dentro da Educação Ambiental, indicam a complexidade da realização desse trabalho pelo professor. A partir do projeto de extensão universitária Educação Ambiental e o trabalho com valores, voltado à formação continuada de professores e realizado de 2008 a 2016 na UNESP de Rio Claro, nos propusemos a compreender os sentidos construídos a seu respeito a partir das lembranças de sete professoras que dele participaram. Nos enunciados das professoras, durante os diálogos que estabelecemos com cada uma delas, a formação se mostrou, de modo geral, relevante, significando a aproximação com novas perspectivas teóricas, momentos de discussões coletivas e atividades variadas, e possibilitando uma reflexão sobre suas práticas pessoais habituais.
\end{abstract}

Palavras-chave: Educação Ambiental. Valores. Formação continuada de professores. Lembranças.

\begin{abstract}
Our research focuses on the in-service teacher training in Environmental Education (EA) and its axiological dimension, considering that several authors who discuss the value dimension within Environmental Education, indicate the complexity of the accomplishment of this work by the teacher. Based on the university extension project Environmental Education and work with values, focused on the In-service teacher training and held from 2008 to 2016 at UNESP in Rio Claro, we set out to understand the senses built on them from the memories of seven teachers who participated in it. In the statements of the teachers, during the dialogues we established with each one, the training was generally relevant, meaning the approach with new theoretical perspectives, moments of collective discussions and varied activities, and allowing a reflection on their habitual personal practices.
\end{abstract}

Keywords: Environmental Education. Values. In-service teacher training. Memories.

\section{Resumen}

Nuestra investigación se concentra en la formación continuada de profesores en Educación Ambiental (EA) y su dimensión axiológica, teniendo en vista que diversos autores, que discuten la dimensión valorativa dentro de la Educación Ambiental, indican la complejidad de la realización de ese trabajo por el profesor. A partir del proyecto de extensión universitaria Educación Ambiental y el trabajo con valores, volcado a la formación continuada de profesores y realizado de 2008 a 2016 en la UNESP de Río Claro, nos propusimos a comprender los sentidos construidos a su respecto desde de los recuerdos de siete profesoras que participaron en él. En los enunciados de las profesoras, durante los diálogos que establecemos con cada una de ellas, la formación se mostró, de modo general, relevante, significando la aproximación con nuevas perspectivas teóricas, momentos

\footnotetext{
${ }^{1}$ Doutoranda no Programa de Pós-Graduação em Ensino de Ciências, Universidade Federal do Mato Grosso do Sul (UFMS), Instituto de Física - Cidade Universitária, Campo Grande, MS; Mestre em Educação - Linha de Pesquisa: Educação Ambiental (UNESP - Rio Claro). E-mail: gabriela.longo28@ hotmail.com

${ }^{2}$ Bióloga, Mestre em Conservação e Manejo de Recursos, Doutora em Educação (CECH - UFSCar) e Livre Docente em Educação Ambiental (UNESP/Rio Claro). Professora do Programa de Pós-Graduação em Educação - Linha de Pesquisa: Educação Ambiental, do Instituto de Biociências UNESP - Rio Claro. E-mail: dalvambb@rc.unesp.br
} 
de discusiones colectivas y actividades variadas, y posibilitando una reflexión sobre sus prácticas personales habituales.

Palabras clave: Educación Ambiental. Valores. Formación continuada de profesores. Recuerdos.

\section{Introdução}

Convivemos, diariamente, com os produtos e a atuação de um desenvolvimento científico, tecnológico e econômico caracterizado pela apropriação do meio ambiente e seus elementos, porém nos concentramos apenas nos produtos, sem pensar nos processos de produção e influências que estes exercem sobre o meio e sobre as pessoas.

Diante da formação dessa crise ambiental, que traz consequências prejudiciais à continuidade da vida, pesquisadores nos levaram a reconhecer e concordar que é necessário repensarmos a relação estabelecida entre o ser humano e os demais elementos da natureza (GONÇALVES, 1998; GRÜN, 2004), uma vez que a problemática ambiental se constitui a partir da forma pela qual concebemos a natureza e, a partir dessa concepção, nos vemos separados dela (BORNHEIM, 1985; CARVALHO, 2012).

É importante considerarmos, ainda, que alguns autores destacam o fato de que nos encontramos em um processo de crise que possui, além da questão ambiental, um componente social inserido. Isso se constitui a partir da ideia de que as questões sociais e ambientais se encontram ligadas em sua gênese e também em suas consequências, caracterizando, assim, uma crise socioambiental (GUIMARÃES, 2004; LIMA, 2004).

Frente a esse quadro, a Educação Ambiental (EA) é tida como uma das possibilidades de enfrentamento dessa crise (CARVALHO, 1989). Desde as últimas décadas do século XX, a EA vem se consolidando como um campo de estudo e de atividade, que tem por um de seus objetivos construir a relação entre a educação, a sociedade e ambiente, procurando formular respostas, no âmbito educativo, aos desafios postos pela realidade da crise mencionada (LIMA, 2004).

Nesse contexto, procurando abarcar diferentes dimensões da realidade humana dentro da EA, situada enquanto crítica (GUIMARÃES, 2004), Carvalho (1989, 2006) propõe um modelo teórico com o intuito de oferecer algumas orientações para a construção e elaboração de práticas em Educação Ambiental, assim como para a formação de professores voltada a essa temática. Nesse modelo, o autor identifica três dimensões como constituintes do processo educativo e, em consequência, também para os processos de EA. Vistas como dimensões de complementaridade e de reciprocidade, o autor as apresenta como: 1- a dimensão relacionada à "natureza dos conhecimentos"; 2- a dimensão axiológica de nossa existência, ou seja, relacionada à valores éticos e estéticos; 3- o tratamento dado às possibilidades de "participação política do indivíduo" (CARVALHO, 2006, p. 26-27).

O diagrama apresentado na Figura 01 procura sistematizar a condição de reciprocidade entre essas dimensões e, a partir dele, se torna possível "explorar alguns aspectos de cada uma dessas dimensões assim como algumas das possíveis relações que se estabelecem entre elas" (CARVALHO, 2006, p. 7). 




Figura 01 - Proposta para práticas com a Educação Ambiental crítica

Fonte: Carvalho $(1989,2006)$

Consideramos, assim, que o conteúdo valorativo está subentendido no interior da crise socioambiental, referida anteriormente, a qual exige mais que a conservação do ambiente: requer o redimensionamento do lugar do ser humano na natureza (GRÜN, 2004). Em nosso trabalho, nos voltamos, então, à questão valorativa como foco de estudo dentro da EA e da formação de professores.

\section{O trabalho educativo com valores}

Nos aproximamos primeiramente de Grün (2004), que indica o fato de que as questões valorativas na Educação Ambiental (EA) vêm se constituindo como uma forma de reflexão sobre os valores que regem a ação humana e sua relação com os demais elementos da natureza.

Adentrando a área da axiologia, Payá (2008) define valores como qualidades que um sujeito atribui a um objeto. A autora explica que o processo de valoração envolve tanto sujeito quanto objeto, uma vez que um dado objeto pode ter valor diferente para diferentes indivíduos.

Assim como a autora, nos apoiamos também em Frondizi (1995), quando o autor explica que existem qualidades sem as quais os objetos não existem, isto é, qualidades consideradas essenciais como tamanho ou peso, que são as qualidades primárias. Junto a estas, estão as qualidades secundárias, ou qualidades sensíveis, como cor ou odor, por exemplo. Os valores classificariam como qualidades terciárias, ou, como o autor destaca ser mais apropriado, nas qualidades irreais, já que não agregam realidade ao objeto. Essas qualidades, ou valores, não são propriedade dos objetos em si, mas dependem do valor dado por um sujeito ao objeto em questão (VÁSQUEZ, 2000), assim, o valor dado a um objeto varia de acordo com o sujeito, mas não muda a estrutura ou definição do objeto por si só. Ao falarmos de sujeito, é importante lembrar que este se situa em dada sociedade, com isso, suas escolhas se dão sempre dentro de um contexto social que o influencia.

A partir do entendimento do que são valores, vemos a necessidade de compreender, também, o que são a ética e a estética, que são parte integrante da dimensão axiológica. A ética se relaciona ao conceito de moral, uma vez que, de modo geral, é considerada uma reflexão sobre a mesma. Sendo que valores morais são aqueles que intermediam as relações em dada sociedade, relacionando o campo social e o cultural, como explicado por Vásquez (2000), e envolvendo as regras sobre o que deve e não deve ser feito na relação com o outro.

Nesse contexto, os indivíduos se deparam com a necessidade de pautar o seu comportamento por normas que julgam ser mais apropriadas (VÁSQUEZ, 2000). Segundo esse autor, a ética irá se encontrar com uma experiência histórico-social no terreno da moral, 
ou seja, com uma série de práticas morais já em vigor e, partindo delas, procurará refletir sobre e determinar a essência da moral, sua origem e condições. O sujeito é regido, então, por valores morais, que se relacionam à sua cultura e ao contexto histórico-social em que está inserido.

Buscando o significado de estética, esta é definida por Hermann (2005) como uma sensação, sensibilidade, percepção pelos sentidos ou como um conhecimento sensívelsensorial.

A estética pode se relacionar com a moral e a ética na medida em que a experiência estética pode nos proporcionar uma sensibilização moral (MUHLE; CARVALHO, 2016). Ou seja, a possibilidade do estabelecimento de uma relação considerada moralmente correta por um caminho relacionado à emoção e à sensibilidade. E, como explica Hermann (2005), esse é um importante caminho para a construção de valores, quando propomos a superação de modos de vida baseados inteiramente na razão.

Compreendemos, então, que a construção do sistema de valores de uma pessoa se dá em meio à sociedade em que vive, de forma que se torna possível constituir uma relação entre a educação e essa construção, através de um trabalho coletivo e baseado no diálogo. Esse trabalho educativo também deve ser específico, com diferentes estratégias de ensino, provindas de diferentes abordagens teóricas (PUIG, 1998).

Pautando-nos em Araújo (2007, p. 35), ressaltamos que o universo educacional deve estar permeado de possibilidades de convivência cotidiana com os valores nas relações interpessoais, de modo que o modelo de educação moral não seja baseado na imposição de determinados momentos e conteúdos, pois o autor considera que "a construção de valores morais se dá a todo instante, dentro e fora da escola".

Contudo, é importante considerarmos a intencionalidade da prática voltada à educação em valores na escola. Dessa maneira, Puig (2004) traz o conceito de práticas morais a serem trabalhadas no ambiente escolar para a construção de valores. Segundo o autor,

Uma prática efetua, realiza ou atualiza os bens ou valores que lhe são inerentes: uma prática é uma ação moralmente informada, daí não serem as práticas um meio para produzir bens ou valores desejados, mas o próprio lugar onde tais valores são incorporados e vividos. Realizamos as práticas para obter um resultado - seus objetivos -, mas realizamos a prática para atualizar e viver determinados valores sua finalidade (PUIG, 2004, p. 75).

O autor explica que as práticas morais são cursos de acontecimentos culturalmente estabelecidos, que permitem o enfrentamento de situações significativas, complexas ou conflitantes do ponto de vista moral, e que as práticas supõem a ação combinada de diferentes sujeitos, ou seja, "que entre as execuções de cada um dos atores se tenha criado uma ligação que trame um acontecimento sociocultural" (PUIG, 2004, p. 71).

Assim, as práticas morais abrem espaço para repensarmos os valores, refletirmos sobre eles e até mesmo ressignificá-los, visto que elas proporcionariam vivência e recriação do instituído ao mesmo tempo e, além disso, o fazem de forma intencional.

No que diz respeito à Educação Ambiental, foco de trabalho de nossa pesquisa, as estratégias descritas por Puig (2004) mostram-se apropriadas também para este campo de trabalho, que necessita de propostas educativas que desvendem modos de vida mais justos, através de atividades coletivas, que incentivem o diálogo e a reflexão. Em vista disso, nos voltamos ao trabalho com a EA e a dimensão de valores.

Grün (2004) explica que certos valores que uniam o ser humano ao meio natural, tendo-o como parte integrante da natureza, foram reprimidos em nossa sociedade, uma vez que vivemos em uma tradição dominante do racionalismo cartesiano. Segundo Grün (2004, p. 24), esse novo momento da ciência evita a associação com a sensibilidade e considera que "a 
predominância do humano sobre todas as coisas e criaturas do mundo tem seu marco filosófico moderno fundamental no pensamento de Descartes".

É explicado pelo autor que uma ética antropocêntrica está intimamente associada ao pensamento cartesiano e à ciência moderna, a qual se afirma em consonância com uma virada epistemológica, caracterizada pelo abandono da concepção organísmica da natureza, que era uma concepção que tornava o ser humano parte da mesma, em favor de uma visão mecanicista. Assim, o mecanicismo consegue legitimar a unidade da razão às custas da objetificação da natureza, problema central da crise socioambiental, tratada anteriormente, já que os seres humanos retiram-se da natureza e esta se torna não muito mais que um objeto à espera do corte analítico.

Entendendo a necessidade de trabalharmos, em sala de aula, valores e valorações que nos aproximem da natureza de forma mais apropriada, nos remetemos a Bonotto (2005) A autora identifica valores ambientalmente desejáveis junto aos princípios que constam no Tratado de Educação Ambiental para Sociedades Sustentáveis e Responsabilidade Global, elaborados pela sociedade civil e apresentados durante a ECO-92. Basicamente, eles se relacionam à pensamentos que envolvem a valorização da vida, valorização da diversidade cultural, valorização das diferentes formas de conhecimentos e à valorização de uma vida sustentável e participativa.

A autora considera, entretanto, esse rol de valores incompleto, por faltar o destaque à valorização estética da natureza. A experiência estética é entendida como uma "possibilidade de relação ser humano-natureza desinteressada, oposta à visão sujeito-objeto, de caráter reducionista e utilitário" (BONOTTO, 2005, p. 4). Portanto, é na articulação do valor estético da natureza aos éticos, anteriormente identificados, que a autora estrutura o conjunto básico de valores a serem trabalhados em EA e no qual baseamos este trabalho.

Ao refletirmos sobre isso, percebemos a complexidade do trabalho com a EA e sua dimensão de valores. Junto a esse desafio, consideramos fundamental pensar o diálogo como o eixo central do processo que se vincula às práticas de EA e valores no contexto escolar.

Nessa perspectiva, a construção de diálogos na interação professor/aluno é fundamental, uma vez que a relação estabelecida entre eles é a chave da construção de conhecimentos e valores. Por isso, tomamos como referência Bakhtin (2009, p. 36), que considera que a "palavra é o modo mais puro e sensível da relação social". O autor entende que

[...] a palavra penetra literalmente em todas as relações entre indivíduos, nas relações de colaboração, nas de base ideológica, nos encontros fortuitos da vida cotidiana, nas relações de caráter político etc. As palavras são tecidas a partir de uma multidão de fios ideológicos e servem de trama a todas as relações sociais em todos os domínios. É, portanto, claro que a palavra será sempre o indicador mais sensível de todas as transformações sociais, mesmo daquelas que apenas despontam, que ainda não tomaram forma, que ainda não abriram caminho para sistemas ideológicos estruturados e bem-formados (BAKHTIN, 2009, p. 42).

Nesse sentido, acreditamos que a partir do diálogo é possível o acontecimento da transformação que procuramos por meio do trabalho com a EA crítica. Portanto é essencial dar voz ao educando, para que ele participe e se posicione em questões valorativas, possibilitando que ele se envolva na construção tanto de conceitos como de valores, de forma que estes tenham significado em sua vida (DEGASPERI; BONOTTO, 2012).

A partir dessas considerações, e compreendendo a necessidade de a EA ser inserida no ambiente escolar brasileiro, chamamos a atenção para mais um desafio que precisa ser devidamente enfrentado se quisermos promover uma EA que possua um aspecto crítico e transformador: a formação de professores, sujeitos que têm um papel fundamental na efetivação desse compromisso. 


\section{A formação de professores}

Inicialmente, é fundamental compreendermos que o professor, para se constituir como tal, passa por diversos passos em sua história, formação e constituição como um educador. Sua formação vai além dos conhecimentos a serem utilizados em seu trabalho; consiste, também, em uma preparação para as diversas funções e exigências que lhe são conferidas dentro da escola.

Assim, é responsabilidade do docente e de sua formação a construção de sua capacidade reflexiva e de elaboração de conhecimento profissional em relação ao conteúdo de sua profissão, bem como sobre os contextos que condicionam sua prática. Dessa maneira, a competência profissional do professor vai além da técnica, já que é, também, intelectual, relacionando-se a sua capacidade de reflexão e de desenvolvimento do conhecimento a partir de suas experiências.

Nessa perspectiva, seria incoerente manter o ensino nos moldes da racionalidade técnica, que, como destacado por Schön $(1983$, 1992) foi, por muito tempo, o modelo dominante de atuação dos profissionais na prática escolar, na relação entre pesquisa, conhecimento e prática profissional, e, ainda, no ensino universitário.

Segundo Contreras (2002, p. 90-91),

A ideia básica do modelo de racionalidade técnica é que a prática profissional consiste na solução instrumental de problemas mediante a aplicação de um conhecimento teórico e técnico, previamente disponível, que procede da pesquisa científica. É instrumental porque supõe a aplicação de técnicas e procedimentos que se justificam por sua capacidade para conseguir os efeitos ou resultados desejados.

A prática suporia, então, a aplicação inteligente de um conhecimento aos problemas enfrentados pelo profissional, com o objetivo de encontrar uma solução satisfatória. Dessa maneira, a relação entre a prática e o conhecimento, ou seja, a teoria, é hierárquica. Porém, compreendemos que o papel da teoria, assim como apresentado por Pimenta (2002), seja o de oferecer aos professores perspectivas de análise para compreenderem os contextos históricos, sociais, culturais, organizacionais e de si mesmos como profissionais, nos quais se dá sua atividade docente, para neles intervir, transformando-os. Ou seja, a teoria, assim como a prática, é de fundamental importância.

Entendemos que o trabalho do profissional da educação, assim como sua formação, não deve privilegiar apenas um desses aspectos. A teoria e a prática devem formar uma relação de equilíbrio que abra espaço para a reflexão.

Dessa maneira, concordamos com André (2001) quando a autora afirma que, quando se trata da formação docente, a problemática da articulação entre teoria e prática é, sem dúvida, uma das questões centrais. A autora esclarece que a forma de lidar com a articulação teoria-prática na formação docente vai depender da história dos sujeitos participantes, do processo de constituição da sua subjetividade, do contexto em que vivem e trabalham, assim como do suporte a eles oferecido.

Nesse sentido, nos aproximamos de um eixo que tem tomado conta de algumas teses que tratam da formação de professores: a ideia do profissional reflexivo.

Segundo Contreras (2002), a teoria do profissional reflexivo trata, justamente, de dar conta da forma pela qual os profissionais enfrentam as situações que não se resolveriam por meio de repertórios técnicos ou, ainda, aquelas atividades que, com o ensino, se caracterizam por atuar sobre situações que são incertas, singulares e nas quais há conflitos de valor.

Zeichner (1993) compreende a ação reflexiva como uma consideração ativa, persistente e cuidadosa daquilo em que se acredita ou se pratica, à luz dos motivos que o justificam e das consequências a que conduz. Ainda segundo o autor, a ação-reflexão implica, 
além de tudo, intuição e emoção, e não um conjunto de técnicas que podem ser empacotadas e ensinadas. Entende-se, assim, que ao dicotomizar teoria e prática, separa-se a reflexão da ação, além de ignorar o contexto em que a prática acontece.

$\mathrm{O}$ autor explica, ainda, que reflexão também significa o reconhecimento de que a produção de conhecimentos sobre o que é um ensino de qualidade não é propriedade exclusiva das universidades e centros de investigação e desenvolvimento, e que os professores também têm teorias que podem contribuir para uma base codificada de conhecimentos do ensino.

Entendemos, então, que o ensino como prática reflexiva valoriza a prática à luz da consideração e observação de uma teoria que esteja imersa no contexto atual, porém que não seja desvinculada da história que a levou até ali.

Vemos, portanto, que a ideia de se aliar a prática docente com a reflexão se distancia do modelo de racionalidade técnica, apresentado anteriormente. Na mesma perspectiva, um modelo que se contrapõe a esse é o da racionalidade prática. Surgido na década de 1980, nesse modelo o professor é visto como alguém que reflete a própria prática, produzindo conhecimentos sobre ela (VIANA et al., 2012).

Porém, para muitos autores, nesse modelo o professor ainda reflete de forma descontextualizada, como se sua prática não estivesse ligada a um contexto social externo à sala de aula. Assim, nos aproximamos de outro modelo, chamado de racionalidade crítica. Tal posicionamento adiciona o adjetivo social aos sentidos de teoria e prática, "ressignificando-os em direção a perspectivas que pensam a escola como uma instituição social" (VIANA et al., 2012, p. 25).

Esse último modelo se aproxima da interpretação de Zeichner (1993) a respeito da prática reflexiva. Segundo o autor, os termos prática reflexiva e ensino reflexivo se tornaram slogans na formação de professores, tendo havido muita confusão a respeito do termo reflexão. Para ele, a noção de reflexividade e de formação docente reflexiva só tem sentido se estiverem vinculadas às lutas mais amplas por transformação social.

O conceito de racionalidade crítica proposto por Contreras (2002) se aproxima, então, das ideias de Zeichner, uma vez que, nessa perspectiva, o professor deve

\section{[...] desenvolver um conhecimento sobre o ensino que reconheça e questione sua natureza socialmente construída e o modo pelo qual se relaciona com a ordem social, bem como analisar as possibilidades transformadoras implícitas no contexto social das aulas e do ensino (CONTRERAS, 2002, p. 157-158).}

Na visão do autor, não é possível compreender as possibilidades que a reflexão tem em si mesma para perceber os interesses de dominação da prática escolar e para transcender os limites que esta impõe à emancipação, se não levarmos em conta a forma como professores e professoras, no contexto da instituição escolar, constroem o seu papel.

Então, sob uma base de crítica à estrutura institucional e os limites que esta impõe à prática de professores, o autor explica que a reflexão feita de forma crítica amplia o seu alcance, incluindo os efeitos que essas estruturas exercem sobre a forma pela qual os professores analisam e pensam a própria prática, bem como o sentido social e político aos quais obedecem.

Desse modo, o caminho aberto pela necessidade da reflexão a ser realizada de forma crítica, como um conhecimento e uma prática a serem tratados em sua formação, torna possível, nos níveis teórico e prático, um novo modo de ver, perceber e atuar na formação de professores.

Em relação a isso, Nóvoa (1992, p. 13) afirma que a formação de professores não se constitui por uma "acumulação (de cursos, de conhecimentos ou de técnicas), mas sim através de um trabalho de reflexividade crítica sobre as práticas e de (re)construção permanente de uma identidade pessoal". 
Para o autor, estar em formação também implica um investimento pessoal, um trabalho livre e criativo, tendo em vista uma construção de sua própria identidade, que é, do mesmo modo, sua identidade profissional. Similarmente, Marcelo (1999), ao apresentar certas conclusões a respeito do conceito de formação, indica que este inclui uma dimensão pessoal de desenvolvimento humano global, diferenciando-se de outras concepções puramente técnicas.

Assim, para os professores conseguirem envolver em sua formação todos esses aspectos, incluindo a dimensão pessoal, necessitam de um processo permanente de desenvolvimento profissional, envolvendo a formação inicial e a continuada. Mendes e Romanowski (2006) consideram que essa dimensão é tida como necessidade fundamental para o exercício da docência, visto que novas demandas são diariamente impostas à educação e, consequentemente, aos professores.

Compreendemos, então, a formação de professores como um processo que acontece ao longo de suas vidas e que deve contemplar tanto especificidades, quanto necessidades da profissão, ou seja, o saber e o saber-fazer, quanto com o ser professor, sua identidade como sujeito e como educador (BONOTTO, 2003).

É importante, também, discutir a caracterização de formação continuada adotada neste trabalho. Seguimos a perspectiva defendida também por Bonotto (2003), que se refere a esse tipo de formação como uma experiência realizada posteriormente à graduação ou magistério (denominadas de formação inicial), em uma fase que os professores já se encontram em exercício da profissão. A autora, apoiada em outros pesquisadores da área, entende a ideia de continuidade desse tipo de formação articulada a uma noção que supera a visão dicotômica de formação inicial/formação contínua, em que a formação em si é vista como "um processo de desenvolvimento profissional da docência, uma aprendizagem da docência que se realiza ao longo da vida do professor" (BONOTTO, 2003, p. 78, grifos da autora).

Entendida dessa forma, a formação continuada propicia o entrelaçamento dos percursos formativos e, assim, a interação de diferentes dimensões, etapas da carreira, contextos e campos de conhecimento, num processo contínuo de aprendizagem (MONTEIRO, 2005).

Voltando-nos especificamente à formação continuada de professores em Educação Ambiental (EA), objeto de estudo deste trabalho, entendemos que essas iniciativas de formação devem se basear em propiciar ao professor uma reflexão crítica a respeito da dimensão ambiental, de sua inserção no trabalho educativo e da discussão a respeito da crise socioambiental, citada anteriormente.

O trabalho pedagógico com a EA traz consigo a necessidade de acrescentar novas técnicas e saberes à escola. Assim sendo, a formação voltada à essa temática se torna fundamental.

\section{A pesquisa}

A fim de nos aproximarmos de uma iniciativa de formação continuada que se volte à EA, é fundamental compreendermos que, se queremos saber como realizar um trabalho qualquer, um procedimento enriquecedor é aprendê-lo com aqueles que efetuam esse trabalho. Nesse sentido, Tardif (2012) destaca um ponto fundamental para entendermos as limitações e possibilidades na formação docente: reconhecer que os professores são sujeitos do conhecimento e que eles deveriam ter o direito de dizer algo a respeito de sua formação profissional. Apontamos, em concordância, a relevância de atentarmo-nos para experiências de formação destacadas pelos próprios professores. O que eles têm a dizer sobre essa experiência? Isso nos levou à pesquisa cujo recorte apresentamos nesse artigo. 
A partir da problemática anunciada, o objetivo do trabalho foi compreender os sentidos construídos por professores, participantes de um programa de formação continuada, sobre a formação vivenciada com a temática discutida, ou seja, Educação Ambiental e sua dimensão de valores. Para este artigo trazemos um recorte da pesquisa, analisando esses sentidos a partir de suas lembranças sobre a experiência vivida.

A presente pesquisa se baseia em uma abordagem qualitativa de análise (BOGDAN; BIKLEN, 1994). Para a constituição dos dados de pesquisa, partimos do diálogo com os participantes do processo formativo, estabelecido durante entrevistas que realizamos com cada um, considerando o diálogo como fundamental para a compreensão de sentidos produzidos sobre o processo de formação que vivenciaram.

Nesse contexto, a filosofia da linguagem proposta por Bakhtin nos permite analisar e compreender os enunciados e os sentidos produzidos nos diálogos. Bakhtin possui uma "percepção da linguagem como produção de sentido" (FREITAS, 2003, p. 144), uma concepção interativa da linguagem, em que a mesma é vista como uma prática social, estabelecida dentro de um contexto histórico-social.

Quanto aos enunciados, segundo Fiorin (2008, p. 30), "todos os enunciados constituem-se a partir de outros". O autor esclarece que um enunciado é sempre heterogêneo, pois revela duas posições, a sua e aquela em resposta à qual ele se constrói, ou seja, a de um enunciador (emissor) e a de um enunciatário (receptor). Assim, consideramos a importância da relação estabelecida, através do diálogo, entre o pesquisador e o sujeito da pesquisa. Ou seja, a construção dos sentidos ocorre no decorrer da relação estabelecida através do diálogo constituído entre pesquisador e professor durante a entrevista.

O projeto de extensão ao qual a pesquisa é vinculada, Educação Ambiental $e$ o Trabalho com Valores, foi realizado junto ao Departamento de Educação do Instituto de Biociências da UNESP, campus de Rio Claro, tendo sido cadastrado junto à PROEX (PróReitoria de Extensão) da UNESP. O projeto teve seu início em 2008, e buscou articular a formação continuada de professores, oferecendo programas de formação estruturados sob diferentes formatos, e a investigação a respeito da prática docente relativa à temática da EA e valores. O primeiro modelo organizado pelo projeto foi um curso, dentro da formatação habitual, contendo uma programação previamente estabelecida para ser desenvolvida ao longo do ano. No decorrer dos anos que se seguiram foram contemplados outros modelos de formação, como oficinas, colóquios e ciclos de estudo, esses últimos, também projetados para ocorrerem em blocos, ao longo de um ano letivo, permitindo uma maior flexibilidade na programação e possibilitando um atendimento maior aos interesses e necessidades dos participantes.

Vimos, portanto, a possibilidade de realizar nossa investigação a partir desse projeto de formação continuada, que tem como temática central a EA e sua dimensão de valores, permitindo aos professores que o vivenciaram falar sobre os sentidos construídos a partir dessa experiência, nesse texto focado em suas lembranças do processo formativo.

\section{Lembranças de um projeto de formação continuada}

Como mencionado anteriormente, utilizamos entrevistas como forma de dialogarmos com as professoras, em busca dos dados de interesse para a pesquisa. Não temos a ilusão, como bem adverte Silveira (2002), de que encontraremos verdades nos enunciados das professoras entrevistadas, mesmo tendo tomado alguns cuidados, como não se fazer referências aos coordenadores do projeto de extensão durante a realização das entrevistas, o que poderia inibir a fala de alguma professora. Outro cuidado foi a tentativa da entrevistadora, antes de iniciar a entrevista, de procurar deixar as professoras à vontade para apresentarem opiniões e críticas, esclarecendo que com isso poderiam colaborar com projetos futuros. 
Reconhecemos, apoiados na perspectiva bakhtiniana de produção de sentidos, que "o sentido da palavra é totalmente determinado por seu contexto"(BAKHTIN, 2009, p.109) e, assim, compreendemos que os enunciados dos professores, durante o que chamamos de diálogos estabelecidos com cada uma delas, se deram nesse contexto limitado das entrevistas efetuadas. Mas, apesar disso, e conscientes desse contexto e dessa limitação, podemos construir alguns sentidos a respeito da experiência que vivenciaram e que podem ser significativos para a presente pesquisa.

Assim, foram selecionados sete professores, de modo que diferentes disciplinas fossem contempladas com os sujeitos escolhidos. Além disso, procuramos selecionar professores que participaram da formação em anos variados e com diferentes níveis de envolvimento em relação ao projeto, assim poderíamos nos aproximar de visões diversificadas a respeito do programa formativo oferecido. Porém, apesar da tentativa de diversificarmos a escolha dos participantes, ao final selecionamos apenas professoras do gênero feminino, algo que se deve ao fato de ser a maioria presente nas atividades do projeto. Tentamos o contato com um dos poucos participantes do gênero masculino, mas não foi possível a sua participação na pesquisa.

A fim de preservar a identidade, alteramos os nomes de cada professora participante. No Quadro 01 apresentamos informações à respeito das entrevistadas.

\begin{tabular}{|c|c|c|c|}
\hline Nome & Disciplina que leciona & $\begin{array}{c}\text { Ano(s) de } \\
\text { participação no } \\
\text { projeto }\end{array}$ & $\begin{array}{c}\text { Tempo de } \\
\text { participação no } \\
\text { projeto }\end{array}$ \\
\hline Christine & Polivalente & 2013 e 2014 & 2 anos \\
\hline Loise & Ciências & 2008,2009 e 2010 & 3 anos \\
\hline Marie & Polivalente & 2013 & 1 ano \\
\hline Francisca & Polivalente & 2015 & 4 anos \\
\hline Dionísia & Artes & $2013,2014,2015$ e & 1 ano \\
\hline Rose & $\begin{array}{c}\text { Filosofia, Sociologia e } \\
\text { Projeto de Vida }\end{array}$ & 2016 & 1 ano \\
\hline Henriqueta & Língua Portuguesa & 2008 & \\
\hline
\end{tabular}

Quadro 01 - Relação das professoras participantes da pesquisa Fonte: arquivos da pesquisa

A fim de rememorar lembranças, ideias e assuntos relacionados à experiência formativa que viveram junto ao projeto, pedimos, inicialmente, que as professoras contassem um pouco sobre suas recordações a respeito da temática e da própria formação. São as respostas dadas a essa solicitação inicial que serão focalizadas neste texto.

A prof ${ }^{a}$. Christine destacou que, em seu segundo ano de participação, foram realizadas atividades que relacionavam a temática da Educação Ambiental (EA) e valores à alimentação, e citou uma experiência específica de uma visita a uma empresa ${ }^{3}$ voltada à agricultura natural,

\footnotetext{
${ }^{3}$ Trata-se da empresa Korin, localizada no município de Ipeúna (SP). Segundo o site da empresa, ela foi fundada em 1994, com uma visão que privilegia o equilíbrio entre preservação e uso do ambiente natural. É pioneira na criação do frango Antibiotic Free (AF - sem antibióticos e promotores artificiais de crescimento). Mais informações: http://www.korin.com.br/. Acesso em 27 de janeiro de 2017.
} 
na qual os participantes tiveram a oportunidade de conhecer o modo de produção, as pesquisas e os produtos vendidos pela empresa. A respeito dessa experiência, ela considerou (informação verbal) 4 que "foi bem interessante [conhecer] a forma como eles trabalham".

Ela citou, ainda, que os ciclos de estudos possibilitaram uma mudança em sua visão a partir das discussões realizadas, levando-a:

A prestar mais atenção em tudo que está a nossa volta, nas coisas que estão embutidas né... no discurso, nas propagandas, de alimentação principalmente, com relação às crianças e tentar de alguma forma abrir isso pras crianças, pra que eles percebam (PROF ${ }^{\mathrm{a}}$. CHRISTINE, 2016, s/p).

Como podemos verificar em sua fala, quando foi discutida a questão da alimentação no projeto, procurou-se aproximar o olhar crítico proposto pela EA a esse tema, discutindo-se assuntos como o poder das propagandas e a influência do mercado em nossos valores, hábitos e decisões quanto a uma alimentação saudável ou não saudável, além da possibilidade de vias alternativas de produção de alimento.

Já a prof ${ }^{a}$. Loise comentou, a princípio, que a atividade que mais ficou marcada em sua memória foi uma atividade de Role-Play ${ }^{5}$. A proposta da atividade se apoiou nas atividades de prática de deliberação moral para o trabalho com valores, destacadas por Puig (2004), que é uma das bases teóricas da pesquisa e do projeto de formação. A proposta da atividade é apresentar uma situação com um conflito de valores para que os participantes reflitam e discutam sobre a mesma, colocando-se no lugar dos envolvidos e ampliando, com isso, a capacidade de lidar com conflitos e de compreensão da justiça.

Ela apontou (informação verbal) ${ }^{6}$, também, que o tema em si foi algo muito significativo em sua experiência: "é realmente porque é minha área a de Biologia, é a parte de Educação Ambiental, que é uma área que muito me agrada, é uma área que eu busco muito [trabalhar], e procuro fugir dos estereótipos" (PROFa . LOISE, 2016, s/p).

Entretanto, a professora Loise (2016, s/p) deixou claro que o mais importante, para ela, foi o fato de não ter sido uma formação em um período curto de tempo. Como ela permaneceu e se envolveu por um período longo, considerou que o mais interessante em uma formação realizada a longo prazo "é o fato do professor ter um tempo pra parar pra estudar. Eu acho que isso é muito importante". Ou seja, uma formação que não se dê de forma pontual, aligeirada, mas, pelo contrário, que vá, passo a passo, possibilitando a entrada nos detalhes da teoria, permitindo compreensões cada vez mais abrangentes e uma mudança de visão.

Além disso, avaliou que a ida para a universidade, para participar de um projeto de formação, para ela, é uma valorização da mesma como profissional: "eu acho assim que quando a Universidade chama o professor pra fazer uma parceria com ele é, eu acho, que uma valorização [...]" (PROFa . LOISE, 2016, s/p).

Consideramos a importância dessa questão relacionando-a com o fato destacado por Contreras (2002) de que, na maioria dos casos, os conhecimentos utilizados por professores em sua prática são criados e estabelecidos por outras pessoas. Dessa forma, os professores acabaram por ocupar uma posição subordinada na comunidade discursiva da educação, algo que pode ser alterado com a aproximação do professor com o meio universitário através da sua participação em grupos de trabalho ou mesmo de formação continuada, tal como ocorreu com essa professora.

\footnotetext{
${ }^{4}$ Entrevista concedida por CHRISTINE. Entrevista I. [out. 2016]. Entrevistador: Gabriela Rodrigues Longo. Rio Claro, 2016. 1 arquivo. mp3 (62 min).

${ }^{5}$ Essa atividade é listada por Puig (2004), juntamente com assembleias de classe, sessões de debates, discussão de dilemas e exercícios de compreensão crítica, como práticas escolares de deliberação moral.

${ }^{6}$ Entrevista concedida por LOISE. Entrevista II. [out. 2016]. Entrevistador: Gabriela Rodrigues Longo. Rio Claro, 2016. 1 arquivo. mp3. (47 min).
} 
No entanto, a prof ${ }^{a}$. Marie apresentou, na entrevista, uma opinião diferente das demais quanto a sua experiência e o espaço oferecido pela universidade para os professores da rede básica de ensino, que levanta outras questões importantes a respeito dessa parceira.

Ela considerou que faltou (informação verbal) ${ }^{7}$ "abrir um pouquinho o espaço pra pessoas que não são da Unesp para prosseguir em estudos mesmo dentro da Unesp [...]" (PROF ${ }^{a}$. MARIE, 2016, s/p), ou seja, ela indicou a falta de uma integração maior do professor dentro da própria Universidade, que permitisse um aprofundamento dessa participação dentro da mesma.

Quando questionada sobre a causa de sua crítica, se era por falta de um tempo maior de permanência no projeto, para que conhecesse e se envolvesse mais com o espaço da universidade e do próprio projeto, ela respondeu que "tem a questão do envolvimento e do tempo, mas assim [falta] um apoio maior pro professor mesmo" (PROF ${ }^{\mathrm{a}}$. MARIE, 2016, s/p).

Vale a pena acrescentar que a professora chegou a verbalizar, ao final da formação da qual participara, em um momento de sondagem de quem gostaria de continuar com o grupo no ano seguinte, que a carga horária oficial dos ciclos de estudos era muito pequena e que ela estava mais inclinada a buscar programas de formação com carga horária maior, que teriam mais peso na progressão de carreira. Não podemos desprezar essa preocupação, que é real na vida dos professores, que contam com poucas possibilidades de progressão profissional. No geral, em função de uma pontuação que leva em conta basicamente a carga horária de cursos que realiza ao longo do ano, os professores são mais ou menos beneficiados, razão pela qual essa carga horária passa a ter um significado real na carreira do professor.

Continuando a entrevista com a prof $f^{a}$. Marie, ao falar do que foi mais marcante para ela dentro do projeto, citou que foi o conteúdo com o qual teve contato. Ela apontou claramente seu entusiasmo com os textos e leituras abordados, e que o estudo realizado foi muito satisfatório: "Ah, o que eu mais me interessei pelo curso foi o estudo mesmo. Eu fiquei maravilhada, eu lia os xerox, tudo que ela [a coordenadora do projeto] passou" (PROFa . MARIE, 2016, s/p). Nesse sentido, é possível percebermos uma aproximação com o que foi indicado pela prof ${ }^{\text {a }}$. Loise, que também apontou o tema discutido no curso como uma de suas principais lembranças.

No entanto, o que fica mais perceptível é a variedade quanto ao que cada uma dessas professoras citou como suas experiências mais significativas. Existe uma variedade de aspectos a serem considerados nos programas de formação, que eram constituídos de atividades práticas, discussões e leituras, além de estar aberto a focos variados dentro da temática geral da Educação Ambiental e valores (como, por exemplo, a questão da alimentação e a temática ambiental). Consideramos que, da forma como os programas foram estruturados, a temática pôde ser tratada de diversas maneiras e por diferentes abordagens dentro de iniciativas de formação continuada, contemplando diferentes caminhos de aprendizagem, interesses e pontos de vista.

Na conversa com a prof ${ }^{a}$. Francisca, as questões tratadas em relação à temática da EA também foram destaque (informação verbal) ${ }^{8}$ :

A parte que foi falado da exploração de águas foi bem interessante porque tem coisas que a gente não faz essas relações, que é do consumismo, do capitalismo que estava ali. E depois foi escolhido o tema alimentação e também aí aquela parte toda de agrotóxico... então, achei bem interessante, [tratar sobre] uma alimentação mais saudável (PROF ${ }^{\mathrm{a}}$. FRANCISCA, 2016, s/p).

\footnotetext{
7 Entrevista concedida por MARIE. Entrevista III. [out. 2016]. Entrevistador: Gabriela Rodrigues Longo. Rio Claro, 2016. 1 arquivo. mp3. (32 $\mathrm{min})$.

${ }^{8}$ Entrevista concedida por FRANCISCA. Entrevista IV. [out. 2016]. Entrevistador: Gabriela Rodrigues Longo. Rio Claro, 2016. 1 arquivo. $\mathrm{mp3}$. (25 min).
} 
Em 2015, ano de participação da prof ${ }^{\mathrm{a}}$. Francisca, o programa de formação trabalhou a relação da EA com o tema da alimentação saudável. E, assim como a prof ${ }^{a}$. Christine, a prof ${ }^{a}$. Francisca deu destaque à mudança que essa discussão trouxe para sua vida pessoal como o mais significativo em suas recordações do programa de formação: “Ah, [a questão] de tentar mudar minha própria alimentação, de tentar ver agora quando eu vou comprar as coisas, tentar mesmo pesquisar e pensar né, quanta gente quer ter lucro de algumas coisas que a natureza dá pra gente né" (PROF ${ }^{\mathrm{a}}$. FRANCISCA, 2016, s/p).

A prof ${ }^{a}$. Dionísia, sendo aquela do conjunto de professoras que esteve em contato com o projeto de extensão por mais tempo, e que por isso participou de diferentes programas dentro do mesmo, descreveu lembranças mais diversificadas, mas todas relacionadas à importância da formação para ela, como pessoa e como profissional da educação (informação verbal $)^{9}$ :

Ah essas discussões sabe, mesmo essas dinâmicas, o abrir a mente pra ver possibilidades diferentes, pessoas que pensam como você, que acreditam nas mesmas coisas que você, que... eu acho que ainda tem jeito [de provocar mudanças na sociedade], mesmo diante de todas as dificuldades assim, é um gás novo. Estar estudando também, o fato de ter um tempo pra parar, pensar, não ficar só na rotina da sala de aula. Ampliar mesmo, né, conhecimentos (PROF ${ }^{\mathrm{a}}$. DIONÍSIA, 2016, s/p).

Percebemos, em suas palavras, um sentido de esperança e motivação que as discussões e o espaço de trocas e apoio entre os participantes lhe trouxeram.

Prof ${ }^{a}$ Francisca (2016, s/p) contou que se aproximou das formações oferecidas pelo projeto de extensão a partir da oficina realizada em 2013 e que, já nessa ocasião, ao término da oficina, se identificou com a formação então oferecida: "achei muito legal esse trabalho diferenciado, teve o Role-Play ${ }^{10}$ lá que eu achei muito legal, e o pensamento também das professoras, tudo que foi falado". Evidenciamos a importância dada pela professora ao trabalho diferenciado como uma possibilidade enriquecedora de formação, já que, como destacado por Nóvoa (2002), a formação continuada deve se alimentar de perspectivas inovadoras, que não utilizem apenas as práticas mais costumeiras.

Entre as experiências vivenciadas, a partir das atividades propostas nas oficinas e nos ciclos de estudos dos quais ela participou, várias foram citadas como sendo marcantes em sua formação:

\begin{abstract}
Ai todos esses desafios assim que são colocados, que nem pensar na questão do silêncio, como que a gente vai retratar o silêncio ${ }^{11}$, ou aquela dos olhos fechados também ${ }^{12}$. Nos anos anteriores, essa questão do encerramento, que a gente tinha que preparar uma atividade artística pra montar, [...]. A questão dos alimentos mesmo, no final do ano que a gente fez as mandalas com as frutas, que a gente trabalhou tudo que a gente tinha visto também, ali eles fizeram um café super lindo também ${ }^{13}$ [...]. A visita a Korin ${ }^{14}$, o trabalho deles de buscar coisas que não sejam só [visando] fins lucrativos, pensar no alimento como um todo, que não é só aquilo, o produto final, que é um processo né, que casa justamente com tudo que a gente fala, né [...] $\left(\right.$ PROF $^{\mathrm{a}}$. FRANCISCA, 2016, s/p).
\end{abstract}

\footnotetext{
${ }^{9}$ Entrevista concedida por FRANCISCA. Entrevista V. [out. 2016]. Entrevistador: Gabriela Rodrigues Longo. Rio Claro, 2016. 1 arquivo. mp3. (30 min).

${ }^{10}$ Atividade semelhante à mencionada pela prof ${ }^{a}$. Loise.

${ }^{11}$ Proposta de atividade em que os professores deveriam fazer uma representação do silêncio para cada um, a partir do que foi observado no ambiente externo à sala.

${ }^{12}$ Atividade em que todos os professores foram vendados e puderam caminhar em meio às árvores e um espaço de uma pequena mata localizada na UNESP de Rio Claro. O objetivo era de que eles pudessem explorar seus outros sentidos em relação ao meio, como tato, olfato e audição.

${ }^{13}$ Atividades de encerramento dos ciclos de estudo em diferentes anos.

${ }^{14}$ Visita já mencionada pela prof ${ }^{\mathrm{a}}$. Christine.
} 
Podemos observar, a partir do que fala, a variedade de atividades realizadas nos quatro anos que a professora participou do projeto e a importância disso para ela, além dos momentos citados, de confraternização entre os participantes.

Ela comentou, também, que sempre gostou da temática, que considera interessante a relação da arte com a EA e que encontrou essa relação valorizada dentro das atividades que vivenciou. Suas considerações se referiram a um ponto importante dentro da proposta da formação geral oferecida pelo projeto, que é a valorização da experiência estética frente à natureza, reconhecida como tendo um potencial educativo para o trabalho com valores em geral e para a EA em particular. Ela deve ser vivida pelos professores, estimulando-os a repetir o mesmo com seus alunos. Essa professora reconheceu o destaque dado no programa formativo à relação entre a EA e a o campo disciplinar que leciona, o que foi significativo e ficou marcado para ela.

A prof ${ }^{\mathrm{a}}$. Rose $(2016, \mathrm{~s} / \mathrm{p})$ participou do projeto no ano de 2012, e também mencionou diferentes lembranças dentro de sua experiência (informação verbal) ${ }^{15}$ : "Eu lembro de várias coisas assim. Desde coisas inusitadas até as ideias que foram discutidas e abordadas, trabalhos que foram feitos, as discussões e produções de texto".

Porém, o mais marcante para ela foi a atividade realizada na escola com seus alunos, a partir da proposta elaborada pelo grupo do qual participara, que era uma etapa importante incluída no projeto:

O que, assim, me remete muito a recordação é a culminância do que nós fizemos [na escola], que foi um piquenique né, não lembro se a gente intitulou de solidário, acho que era diferente, um piquenique ecológico que a gente fez na pracinha ali em frente à Igreja Santo Antônio. Ali foi a finalização, era um terceiro ano, eles já estavam pra se formar, era final do ano, então foi meio que a despedida deles, o bota fora, e a culminância do projeto. E, assim, choraram, foi super bonito, a gente fotografou, o dia tava lindo, eles brincaram, foi bem legal, foi singelo. Acho que é isso assim. Eu lembro também das discussões, eu lembro dos conflitos, eu lembro das coisas que eu pensei, mas de forma genérica (PROF ${ }^{a}$. ROSE, 2016, s/p).

Falando de sua experiência, a Prof ${ }^{a}$ Rose $(2016$, s/p) mencionou que participou da fase de registro escrito das experiências ocorridas em 2013, com o propósito de elaboração de um livro, o que veio a se dar com a publicação do e-book ${ }^{16}$ lançado em 2016: "e, ah, eu lembro de tudo, eu lembro do processo de escrever e eu participei bem ativamente assim". A respeito desse processo de escrever, a professora apresentou comentários significativos quanto às dificuldades que enfrentou:

Então, esse foi um sofrimento, porque eu gosto muito de escrever, eu tenho até uma certa facilidade. Eu tive que escrever em conjunto e, na hora de escrever, todo o meu grupo já tinha debandado, então só ficou eu e mais um professor e ele não tem tanta facilidade, ele tem dificuldade. Então, assim, foi difícil fazer junto, mesmo porque algumas ideias dele não eram como as minhas, e no fim acabou que as minhas prevaleceram ali, não por autoridade não, mas porque ele não se posicionava mesmo, então ele meio que foi... então essa foi a parte que me desanimou, assim, foi na hora que eu desencanei do projeto, foi na hora de escrever coletivamente. Eu não digo assim, escrever o livro coletivamente, mas escrever o texto em conjunto sendo que havia conflitos de ideias, no fim eu acabei fazendo mais, eu não gostei, eu me senti meio que, assim, usada. Então foi aí que eu larguei mão, assim, não optei por continuar (PROF ${ }^{a}$. ROSE, 2016, s/p).

\footnotetext{
15 Entrevista concedida por Rose. Entrevista VI. [out. 2016]. Entrevistador: Gabriela Rodrigues Longo. Rio Claro, 2016. 1 arquivo. mp3. (39 $\mathrm{min})$.

${ }^{16}$ BONOTTO, D. M. B.; CARVALHO, M. B. S. S. (Orgs.) Educação Ambiental e valores na escola: buscando espaços, investindo em novos tempos. São Paulo: Cultura Acadêmica Editora, 2016. Disponível em: https://static.scielo.org/scielobooks/85fqc/pdf/bonotto-9788579837623.pdf (Acesso em 27 de outubro de 2020).
} 
O e-book foi idealizado no ano subsequente ao da formação, com o objetivo de revisitar (um objetivo formativo) e documentar a experiência dos professores de implementação do plano de atividades elaborado em pequenos grupos, em que buscaram concretizar em suas práticas os estudos realizados. Visando registrar a descrição e reflexão da experiência vivida, a proposta era a de realizar, em cada capítulo do livro, um texto coletivo, envolvendo os mesmos professores que em um dado subgrupo elaboraram o plano de ensino e o desenvolveram em ao menos uma de suas turmas de alunos. O intuito seria contemplar no texto aspectos comuns e também os particulares da experiência.

A prof ${ }^{a}$. Rose escreveu o texto em conjunto com outro professor de Filosofia participante do projeto. Como nos demais subgrupos, nem todos os professores puderam dar continuidade a esse trabalho no ano seguinte, razão pela qual a prof ${ }^{a}$. Rose contou com apenas mais um colega para a escrita. Porém, a professora apontou que redigiu a maior parte da reflexão.

O trabalho em conjunto sempre foi algo muito valorizado dentro do projeto de extensão, que organizava as formações de modo colaborativo, em que professores da Educação Básica, da universidade, graduandos e pós-graduandos participam das discussões, das leituras e das atividades práticas envolvidas. A partir do comentário da prof ${ }^{a}$. Rose, podemos identificar que essa proposta envolve um processo que, necessariamente, não garante um trabalho coeso e harmonioso para todos os envolvidos, implicando na possibilidade do surgimento de conflitos e outros imprevistos que exigem um olhar atento e sensível por parte dos formadores, buscando resolver, quando possível e o quanto possível, os desafios surgidos.

É interessante mencionar, também, que, além das leituras, o contato com a universidade foi algo muito importante para a professora:

Eu adorei, fazia um tempo que eu estava parada [afastada] já da Universidade, então pra mim foi muito importante, porque foi um retomar, recomeçar né, até assim voltar a estudar, voltar à ativa, porque na escola, ela é muito alienante, então o dia a dia da gente acaba que esse lado, as vezes, ele acaba sendo massacrado, então foi muito bom assim, foi um novo despertar e foi um interesse muito grande na Educação Ambiental (PROF ${ }^{\mathrm{a}}$. ROSE, 2016, s/p).

A partir de sua fala, desponta a discussão a respeito de que, em sua profissão, nem sempre os professores são encorajados a continuar seus estudos e atualizar seus conhecimentos, sendo massacrados pelo dia a dia de trabalho na escola, conforme expôs essa professora. Com isso, identificamos a importância dos projetos de extensão universitária, abrindo as portas da universidade para os professores retomarem o contato com esses espaços, para a ampliação de conteúdos e discussões, possibilitando a continuidade de seus estudos.

A prof ${ }^{a}$. Henriqueta participou do programa em 2008, ano em que a formação ocorreu em formato de curso. E, dando continuidade à formação, participou também do programa que aconteceu em 2010, quando as reuniões coletivas ocorreram na escola em que ela trabalha.

Nessa formação, a professora elaborou a proposta de ensino que consta em um dos capítulos do livro "Educação Ambiental e o trabalho com valores", publicado em $2012^{17}$, que foi fruto das reflexões e discussões do grupo participante do projeto no ano de 2010 , tendo sido a primeira experiência de organizar a formação sob a proposta de escrita coletiva do trabalho realizado em ano anterior. A Prof ${ }^{a}$. Henriqueta (2016, s/p) contou que gostou da proposta de organizarem um livro, por envolver outras áreas além da dela (informação

\footnotetext{
${ }^{17}$ BONOTTO, D. M. B.; CARVALHO, M. B. S. S. (Orgs.) Educação Ambiental e o trabalho com valores: reflexões, práticas e formação docente. São Carlos: Pedro \& João Editores, 2012.
} 
verbal ${ }^{18}$ : “[...] e foi muito legal, acho que foi um dos últimos projetos, assim, grandes que nós fizemos né, porque aí envolveu geografia, envolveu outras áreas, né”.

Porém, ela deu um valor maior à sua experiência em 2008, devido à maior base teórica trabalhada na ocasião: "É, mas assim... a experiência foi ótima, mas eu achei assim que a base teórica também foi muito importante. E a base teórica que foi a de 2008". Além disso, ela cita que o fato do curso de 2008 ter acontecido na Universidade foi muito importante também: "É, aqui [na universidade]. Entendeu? Foi muito importante. Os nossos encontros aqui eram ótimos" (PROFa. HENRIQUETA, 2016, s/p). Mais uma vez, nos deparamos com a valorização do contato com a universidade e com os conhecimentos proporcionados a partir disso.

Do que ela vivenciou no projeto, em toda a sua experiência, a Prof ${ }^{a}$. Henriqueta (2016, s/p) deu um significado muito grande às discussões realizadas: "Eu tenho até hoje, anotado em algum lugar né, assim, os procedimentos e tal, como foi, e... foi muito bom. Eu sempre fui muito ligada nessa questão de meio ambiente, né, desde criança". E é a essa ligação com a questão ambiental que a professora atribuiu um sentimento de interesse para com a temática apresentada no projeto, a partir do qual ela entrou em contato maior com a teoria:

Assim, é como eu te disse, eu tinha esse olhar pra questão ambiental, mas não tinha essa visão teórica, então isso foi muito importante. Outro momento muito importante, foi quando nós trabalhamos em um desses encontros a questão da arte, a arte né, como meio pra você trabalhar o emocional, o afetivo, e fazer essa ligação (PROF ${ }^{\mathrm{a}}$. ROSE, 2016, s/p).

Ressaltamos a importância dada pela professora à teoria trabalhada em sua formação no decorrer do projeto. Tanto no projeto de formação quanto em nossa pesquisa nos aproximamos de Bonotto (2003) e sua proposta para a organização de programas de formação docente. A autora propõe que três aspectos não devem ser negligenciados nessa organização, e um deles é o trabalho com o aprofundamento teórico, para reflexão das práticas a partir dele.

Nesse sentido, a prof ${ }^{a}$. Henriqueta também destaca, em suas palavras, a valorização que dá à compreensão que passa a ter sobre a experiência estética, com seu potencial para proporcionar, entre ser humano e natureza, uma ligação afetiva, implicando em um trabalho com valores voltado à natureza sendo construído nessa relação (BONOTTO, 2008).

Reunindo as lembranças mais significativas das professoras, nos deparamos com um sentido positivo para a maior parte dessas experiências, exceto por dois casos considerados negativos: o pouco apoio dado pela universidade citado por uma delas e a escrita coletiva do livro por outra professora. Várias professoras relataram mudanças pessoais influenciadas pela formação como algo muito importante em sua experiência e houve uma grande valorização das atividades práticas realizadas, como o Role Play e trabalhos que envolveram a experiência estética. $\mathrm{O}$ fato de não ser uma formação de curto período foi algo também apontado como relevante por algumas professoras, embora uma delas tenha colocado o tempo da formação como um contato ainda pequeno com a universidade. Mas algo também muito importante, destacado por cinco das sete professoras, foram as discussões teóricas apresentadas pelo projeto, seu conteúdo teórico em si, implicando ou no aprofundamento de conhecimentos e/ou em uma mudança de visão e até de hábitos pessoais.

É interessante notar que, quanto às suas recordações, foram mencionadas experiências diferentes pelas professoras com relação ao que elas consideraram mais marcantes em sua passagem pelo projeto. No entanto, percebemos certa tendência entre as professoras em reconhecer a base teórica tratada nas discussões como significativa em sua formação.

18 Entrevista concedida por HENRIQUETA. Entrevista VII. [março 2017]. Entrevistador: Gabriela Rodrigues Longo. Rio Claro, 2017. 1 arquivo. mp3. (42 min). 
As colocações realizadas pelas professoras evidenciaram a relevância de formações que sejam diferenciadas e variadas, que destaquem o aspecto da criatividade presente na prática docente, algo colocado por Nóvoa (2002) como fundamental em iniciativas de formação continuada.

É importante levarmos em consideração, também, a proposta de Bonotto (2003), que fundamenta o programa de formação do qual nos aproximamos em nossa pesquisa. Ela foi inspirada nas reflexões sobre a EA e o modelo de três dimensões de Carvalho $(1989,2006)$ e sugere, para a organização de programas de formação docente, a atenção para três aspectos que não podem ser negligenciados.

No primeiro desses aspectos se enquadram as propostas de reflexão apresentadas (por ex. CONTRERAS, 2002; ZEICHNER, 1993). De acordo com a autora, é o trabalho com aprofundamento teórico, para reflexão das práticas a partir dele.

Em um segundo aspecto, a autora pontua que a aproximação com a proposta da educação em valores oferece sugestões para o trabalho com "crenças, atitudes e sentimentos profundamente envolvidos com nossos valores e que fundamentam nossas práticas" (BONOTTO, 2003, p. 96).

Por fim, o terceiro aspecto se relaciona à prática docente, especificamente em termos do desenvolvimento das atividades educativas, ou seja, experiências que devem ser trazidas para o programa formativo e também produzidas a partir dele e com o apoio do programa formativo.

Considerando esses aspectos, os três foram contemplados pelo projeto de formação e são indicados pelas professoras como significativos.

\section{Considerações Finais}

Com exceção de dois enunciados que apontaram para aspectos negativos da experiência vivida, os sentidos que se sobressaíram das considerações apresentadas pelas professoras indicaram que a formação se constituiu em algo prazeroso. Com essa conotação, elas se referiram aos estudos da fundamentação teórica oferecida, assim como a aspectos metodológicos relativos à organização do projeto e dos encontros coletivos realizados. A articulação entre a teoria (textos lidos individualmente, fora das reuniões presenciais) e as discussões realizadas nos encontros foi apontada como importante, assim como o tempo destinado para o programa formativo (que fugiu das propostas muito pontuais) e as possibilidades de trocas de ideias e de atividades realizadas em conjunto com os demais participantes.

Nessa primeira solicitação feita às professoras, ao início da entrevista, e que constituiu o foco deste artigo, não apareceram considerações mais específicas sobre o conteúdo teórico estudado, seja quanto à perspectiva crítica da educação ambiental apresentada na formação, seja quanto à dimensão valorativa e o trabalho educativo com valores.

Isso já possibilitou reconhecer que um domínio mais profundo do referencial teórico ainda esteja por ser feito, demandando mais tempo de formação. No entanto, as referências a respeito da propaganda levando a hábitos alimentares, e outras relativas ao capitalismo e consumismo, indicaram novos sentidos surgidos a partir dos estudos realizados, segundo os depoimentos de algumas professoras, provocando novas posturas e uma visão ampliada e mais crítica frente aos assuntos trabalhados na formação. Indicações sobre a articulação entre a educação ambiental e a área de Artes ou sobre a experiência estética remetem ao conteúdo do programa formativo que focou a questão dos valores e a experiência estética, favorecendo a sua construção, relação que ficou estabelecida para duas professoras.

Ainda sobre essa questão, alguns enunciados deram destaque a uma incorporação pessoal do que foi estudado, no sentido de uma mudança de visão e de hábitos. Consideramos 
que uma formação envolvendo a EA em geral, e a dimensão valorativa em particular, não pode se limitar a um domínio teórico dos assuntos tratados por parte do professor, mas, de certa forma, ele deve fazer sentido em sua própria vida, provocando questionamentos e mudanças. De certa forma, esse processo parece ter se iniciado para algumas das professoras participantes da pesquisa, segundo suas declarações.

Essas considerações, a nosso ver, indicam o início de um processo de saída de uma visão mais superficial da questão ambiental, de acordo com o referencial que adotamos, em que nos vemos externos a ela (e à própria natureza), para uma nova visão em que percebemos a atual sociedade consumista e exploradora, da qual fazemos parte e cujas características precisamos identificar e enfrentar.

No entanto, se de um lado as mudanças referidas podem indicar o processo de ressignificação de valores frente aos assuntos discutidos, levando, em alguns casos conforme exposto, a mudanças de posturas e hábitos, estes se referiram basicamente a um sentido mais pessoal de mudança. Essas pareceram não abranger a prática docente, como se ela não tivesse (ainda?) sofrido essa influência, com exceção de uma única professora, que explicitou sua busca por levar às crianças essa nova visão crítica. Essa compreensão é reforçada em momentos posteriores da entrevista, quando o diálogo focou mais especificamente o trabalho com valores e as falas indicaram dificuldades em realizar esse trabalho, considerado delicado e difícil, ou, em movimento contrário, considerando-o como consequência natural e exclusiva da conduta do professor. Compreendemos esses enunciados como indicativos de que não deve ter ocorrido incorporação significativa dos estudos realizados no programa formativo, o que pode indicar a necessidade de uma maior atenção, em programas de formação docente, a esse conteúdo específico.

É importante, também, ressaltarmos os sentidos envolvendo o contato com o ambiente da universidade, caracterizado como muito positivo, mas algo que parte dos professores perde depois de concluir seus cursos de graduação. Foram apresentadas, nas entrevistas, diferentes visões a esse respeito, mas dentro desses sentidos, acreditamos ter sido significativo o reconhecimento da aproximação viabilizada pela formação continuada no espaço da universidade, o que permite que os professores, inclusive, possam vir a explorar outras oportunidades de formação, como cursos de pós-graduação.

Por fim, encerrando estas considerações, e ao final desta investigação, consideramos ser fundamental indicarmos a importância da inserção da EA e o trabalho com a dimensão de valores na formação continuada de professores. Faz-se necessária a ampliação de discussões, pesquisas e estudos, que possam compreender com profundidade esse processo formativo e viabilizar novos projetos de formação com a temática, assim como o maior desenvolvimento da mesma no ambiente escolar.

\section{Referências}

ANDRÉ, M. E. D. A. Desafios da Pesquisa sobre a Prática Pedagógica. Educação \& Linguagem, São Bernardo do Campo, v. 05, n. 04, p. 51-65, 2001.

ARAÚJO, U. F. A construção social e psicológica dos valores. IN: ARANTES, V. A. (Org.) Educação e Valores: pontos e contrapontos. São Paulo: Summus, 2007. p.17-43 (Coleção pontos e contrapontos).

BAKHTIN, M. (VOLOCHINOV, V. N.). Marxismo e Filosofia da Linguagem. Problemas Fundamentais do Método Sociológico na Ciência da Linguagem. Trad. Michel Lahud e Yara Frateschi Vieira. São Paulo: Hucitec, 2009. 
BOGDAN, R. C., BIKLEN, S. K. Investigação Qualitativa em Educação. Portugal: Porto Editora, 1994.

BONOTTO, D. M. B. O trabalho com valores em Educação Ambiental: investigando uma proposta de formação contínua de professores. 2003. 231f. Tese (Doutorado em Educação) - Centro de Educação e Ciências Humanas, Universidade Federal de São Carlos, São Carlos, 2003.

BONOTTO, D. M. B. O conteúdo valorativo da Educação Ambiental: investigando uma proposta de formação docente voltada para o tema. In: REUNIÃO ANUAL ANPED, 28, 2005, Caxambu: Anais 28 Reunião Anual - Anped, 2005, 16 p. Disponível em:

http://arquivos.ambiente.sp.gov.br/cea/cea/Conteudo Valorativo.pdf (Acesso em: 27 de outubro de 2020).

BONOTTO, D. M. B. Educação ambiental e educação em valores em um programa de formação docente. Revista Electrónica de Enseñanza de las Ciencias, Vigo, v. 7, n. 2, p. 313-336, 2008.

BONOTTO, D. M. B.; CARVALHO, M. B. S. S. (Orgs.) Educação Ambiental e o trabalho com valores: reflexões, práticas e formação docente. São Carlos: Pedro \& João Editores, 2012.

BONOTTO, D. M. B.; CARVALHO, M. B. S. S. (Orgs.) Educação Ambiental e valores na escola: buscando espaços, investindo em novos tempos. São Paulo: Cultura Acadêmica Editora, 2016. Disponível em: https://static.scielo.org/scielobooks/85fqc/pdf/bonotto-9788579837623.pdf (Acesso em: 27 de outubro de 2020.

BORNHEIM, G. Filosofia e Política Ecológica. Revista Filosófica Brasileira, Rio de Janeiro, v.2, n.1, p.16-24, 1985.

CARVALHO, I. C. M. Educação Ambiental: a formação do sujeito ecológico. São Paulo: Cortez, 2012.

CARVALHO, L. M. A temática ambiental e a escola de $1^{\circ}$ grau. 1989. 282f. Tese (Doutorado em Educação) - Faculdade de Educação, Universidade de São Paulo, São Paulo, 1989.

CARVALHO, L. M. A Temática Ambiental e o Processo Educativo: dimensões e abordagens. In: CINQUETTI, H. S; LOGAREZZI, A. (Orgs.). Consumo e Resíduos - Fundamentos para o trabalho educativo. São Carlos, EdUFSCar, 2006. p. 19-41.

CONTRERAS, J. A autonomia de professores. São Paulo: Cortez, 2002.

DEGASPERI, T. C.; BONOTTO, D. M. B. Educação Ambiental e Valores: interações e sentidos construídos nas práticas de professores de ensino fundamental. In: ENDIPE - ENCONTRO NACIONAL DE DIDÁTICA E PRÁTICAS DE ENSINO, 16, 2012, Campinas. Anais ENDIPE. Campinas: UNICAMP, 2012. Disponível em:

https://www.researchgate.net/publication/309155265_Educacao_Ambiental_e_Valores_interacoes_e_ sentidos_construidos_nas_praticas_de_professores_de_ensino_fundamental (Acesso em: $27 \mathrm{de}$ outubro de 2020).

FIORIN, J. L. Introdução ao pensamento de Bakhtin. São Paulo: Ática, 2008.

FREITAS, M. T. A. A perspectiva sócio-histórica: uma visão humana da construção do conhecimento. In: Maria Teresa de a. Freitas; Solange Jobim e Souza; Sônia Kramer. (Org.). Ciências Humanas e Pesquisa: Leituras de Mikhail Bakhtin. 1 ed. São Paulo: Cortez Editora, 2003, v. 107. p. 26-38. 
FRONDIZI, R. ¿Qué Son Los Valores? In: FRONDIZI, R. Introducción a la axiologia. México, Fondo de Cultura Económica, 1995. (Colección Breviarios, 135).

GONÇALVES, C. W. P. Os (des)caminhos do meio ambiente. 6 ed. São Paulo, Contexto, 1998.

GRÜN, M. Ética e Educação Ambiental: a conexão necessária. Campinas: Papirus, 2004.

GUIMARÃES, M. Educação ambiental crítica. In: LAYRARGUES, P. P. (Org.). Identidades da Educação Ambiental Brasileira. Brasília: MMA, 2004. p. 25-34.

HERMANN, N. Estetização do mundo da vida e sensibilização moral, In: Educação e Realidade, Porto Alegre, v. 2, n. 30, p. 11-26, Jul./Dez. 2005.

LIMA, G. F. C. Educação, Emancipação e Sustentabilidade: em defesa de uma pedagogia libertadora para a educação ambiental. In: LAYRARGUES, P. P. (Org). Identidades da Educação Ambiental Brasileira. Brasília, MMA, 2004. p. 85-111.

MARCELO, C. Formação de professores para uma mudança educativa. Porto: Porto Editora, 1999. (Coleção Ciências da Educação - século XXI).

MENDES, K. V. M.; ROMANOWSKI, J. P. Formação Continuada de Professores: os modelos com base na racionalidade técnica. In: EDUCERE - CONGRESSO DE EDUCAÇÃO DA PUCPR, 6, 2006, Curitiba. Anais EDUCERE. Curitiba: Champagnat, 2006.

MONTEIRO, F. M. A. Desenvolvimento profissional da docência: uma experiência de formação. In: REUNIÃO ANUAL ANPED, 28, 2005, Caxambu: Anais 28 Reunião Anual-Anped, 2005.

MUHLE, R. P.; CARVALHO, I. C. M. Experiência estética no Centro de Pesquisas e Conservação da Natureza Pró-Mata-PUCRS. Revista Eletrônica do Mestrado em Educação Ambiental, Rio Grande, v. 37, n. 1, p. 37-64, 2016.

NÓVOA, A. Formação de professores e profissão docente. In: NÓVOA, A. (Org.). Os Professores e a sua formação. Lisboa: Instituto de Inovação Educacional, 1992. p. 13-33.

NÓVOA, A. Formação de professores e o trabalho pedagógico. Lisboa: Educa, 2002.

PAYÁ, M. S. Naturaleza de los valores. In: OLIVEIRA, M. J.; FERREIRA, N. A. (Orgs.). Educação e democracia: fundamentos teóricos para uma abordagem dos valores. Salvador: EDUNEB, 2008. p. 41-64.

PIMENTA, S. G. Professor Reflexivo: construindo uma crítica. In: PIMENTA, S. G.; GHEDIN, E. (Orgs.) Professor Reflexivo no Brasil: gênese e crítica de um conceito. 2 ed. São Paulo: Cortez Editora, 2002. p. 17-52.

PUIG, J. M. Ética e valores: métodos para um ensino transversal. São Paulo: Casa do Psicólogo, 1998. (Coleção Psicologia e Educação).

PUIG, J. M. Práticas morais: uma abordagem sociocultural da educação moral. São Paulo: Moderna, 2004. (Coleção Educação em Pauta - Escola e Democracia).

SCHÖN, D. Formar professores como profissionais reflexivos. In: Nóvoa, A. (Org.). Os professores e sua formação. Lisboa: Dom Quixote, 1992. 158 p.

SCHÖN, D. The reflective practitioner. New York: Basic Books, 1983. 
SILVEIRA, R. M. H. A entrevista na pesquisa em educação - uma arena de significados. In: COSTA, M. V. (Org.). Caminhos Investigativos II - outros modos de pensar e fazer pesquisa em educação. Rio de Janeiro: DP\&A Editora, 2002. p.119-141.

TARDIF, M. Saberes Docentes e Formação Profissional. 14 ed. Petrópolis: Vozes, 2012.

VÁSQUEZ, A. S. Ética. Rio de Janeiro: Civilização Brasileira, 2000.

VIANA, G. M.; MUNFORD, D.; FERREIRA, M. S.; MORO, L. Relações entre teoria e prática na formação de professores: investigando práticas sociais em disciplina acadêmica de um curso nas ciências biológicas. Educação em Revista, Belo Horizonte, v. 28, n. 04, p. 17-49, Dez. 2012.

ZEICHNER, K. Formação Reflexiva de Professores: ideias e práticas. Lisboa: Educa, 1993. 